\title{
BILATERAL SIMULTANEOUS URETERAL TUMORS
}

\author{
MICHAEL W. MCDONALD, M.D. \\ M. HUGH SOLOMON, M.D. \\ JOHN W. KONNAK, M.D.
}

From the Section of Urology, Department of Surgery, The University of Michigan, Ann Arbor, Michigan

\begin{abstract}
A patient with bilateral, simultaneous ureteral tumors is described. A brief comment on therapeutic techniques utilized in previous cases is presented.
\end{abstract}

Ureteral tumors are not a common occurrence in clinical practice. Simultaneous bilateral ureteral tumors are very unusual and raise interesting therapeutic dilemmas. We describe a patient with simultaneous, bilateral ureteral tumors.

\section{Case Report}

A sixty-seven-year-old white woman was referred to the urology service at the University of Michigan with a several-month history of recurrent urinary tract infections. There was no history of gross hematuria or exposure to known urinary carcinogens. An excretory urogram demonstrated bilateral filling ureteral defects suggestive of ureteral tumors (Fig. 1). The patient was admitted to the hospital for further evaluation. Physical examination revealed marked obesity but no other abnormalities. Complete blood count showed hematocrit 40 , hemoglobin $14 \mathrm{Gm} . / 100 \mathrm{ml}$., and white blood cells 5,700 per $\mathrm{mm}^{3}$. Electrolytes in $\mathrm{mEq} / \mathrm{L}$. were sodium 138 , potassium 4.8 , chloride 104 , bicarbonate 30 . Blood urea nitrogen was $21 \mathrm{mg}$. and serum creatinine $1.3 \mathrm{mg} . / 100 \mathrm{ml}$. Liver function tests were within normal limits. Chest roentgenogram was normal, and electrocardiogram demonstrated changes consistent with an old inferior wall myocardial infarction of indeterminate age.

Cystoscopy was performed, and a small papillary tumor was found on the right trigone. Bilateral retrograde pyelograms confirmed the ureteral filling defects. Ureteral washings and brush- ings were obtained and returned no evidence of neoplasm. Bone scan, selected bone films, and pedal lymphangiography did not demonstrate metastatic disease.

The patient underwent a transurethral resection of bladder tumor and left nephroureterectomy with excision of bladder cuff. The nephroureterectomy was done through a flank incision and separate Gibson incision with opening of the bladder. Three weeks later a right distal ureterectomy with ureteroneocystostomy was done through an oblique lower abdominal incision with retroperitoneal exposure. A ureterocutaneous fistula developed from the ureteroneocystostomy; consequently, three weeks after this procedure it was necessary to explore this area, place a Silastic stent through the anastomosis, and close the leak with several sutures. All drainage stopped, and the patient was discharged from the hospital seventy-six days after her first operation.

Pathology report was papillary transitional cell carcinoma in the bladder, left ureter, and right ureter. No invasion was present in any of these areas. Follow-up examination four months after discharge did not demonstrate metastatic disease or bladder tumor recurrence.

\section{Comment}

Although transitional cell carcinoma is considered a field change disease of the transitional epithelium, simultaneous, bilateral ureteral 


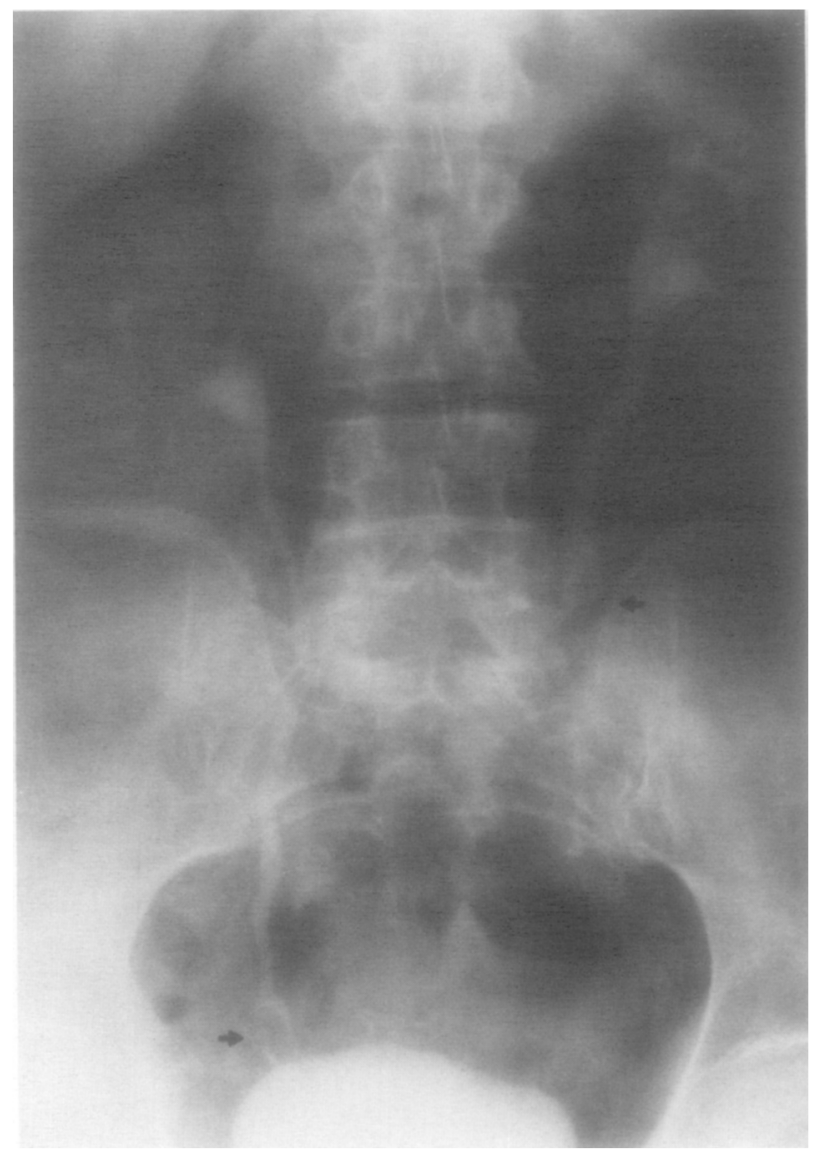

FIGURE 1. Excretory urogram with arrows indicating bilateral ureteral filling defects.

tumors have been reported rarely. In 1931 Chauvin and Romieu ${ }^{1}$ reported 2 personal cases and made mention of a third. Ratliff, Baum, and Butler ${ }^{2}$ from our center, described the first detailed contemporary case. Since that time 13 additional cases have appeared in the English literature. ${ }^{3-13}$

Because of the need to conserve renal function, these patients have been treated conservatively. Therapy must be individualized according to the location and extent of tumor. Operative procedures have ranged from fulguration of tumor protruding from ureteral orifices ${ }^{1}$ to $\mathrm{ex}$ ternsive ureteral resection with autotransplantation. ${ }^{12}$ Six patients, including our own, were treated with nephroureterectomy on one side and conservative surgical procedure on the other. ${ }^{2,3,5,9,10}$ Five patients had conservative procedures bilaterally. ${ }^{6,7,10,13}$ Two patients had bilateral distal ureterectomies with diversion; in 1 case with cutaneous ureterostomies ${ }^{8}$ and in the other with cutaneous ureteroileostomy. ${ }^{11}$ One patient underwent bilateral distal ureterectomies with interposition of an ileal segment between the proximal ureters and the bladder. ${ }^{4}$

We believe that both kidneys should be preserved when possible. In our patient, the location and extent of the left ureteral tumor made segmental resection or excision with ureteroneocystostomy impossible. We did not believe that her general medical condition was such that ureteral replacement with ileum was warranted, and the alternatives of a permanent left nephrostomy or cutaneous ureterostomy were not attractive. Autotransplantation of the left kidney was a theoretical option not seriously considered in this case.

The presence of a bladder tumor in our patient, and in previous reports, ${ }^{8,10,12,13}$ demonstrates again that regular surveillance of the bladder must not be forgotten in patients with ureteral tumors.

Department of Urology The University of Texas System Cancer Center M. D. Anderson Hospital and Tumor Institute Houston, Texas 77030

(DR. MCDONALD)

\section{References}

1. Chauvin E, and Romieu M: Bilateral polyps and papillary adenomata of the ureter, Urol. Cutan. Rev. 35: 415 (1931).

2. Ratliff RK, Baum WC, and Butler WJ: Bilateral primary carcinoma of the ureter: a case report, Cancer 2: 815 (1949).

3. Garcia V, and Bradfield EO: Simultaneous bilateral transitional cell carcinoma of the ureter: a case report, J. U rol. 79: 925 (1958).

4. Crassweller PO: Bilateral primary carcinoma of the ureter with use of ileal graft for ureteral replacement: case report, $\mathrm{Br}$. J. Urol. 30: 152 (1958)

5. Viek NF, Uhlman RC, and Verrilli R: Simultaneous bilateral transitional cell carcinoma of the ureters, J. Urol. 89: 49 (1963).

6. Perlmutter AD, Retik AB, and Harrison JH: Simultaneous bilateral carcinoma of the ureter present for five years before surgery, ibid. 93: 582 (1965).

7. Barroso CJ Jr, Florence TJ, and Scott C Jr: Bilateral papillary carcinomas of the ureters: presentation of a case and 2 vear followup report, ibid. 96: 451 (1966).

8. Gillenwater JY, Howard RS, and Paquin AJ: Bilateral primary carcinoma of the ureter, JAMA 197: 1040 (1966)

9. Barber JW: Bilateral simultaneous primary carciroma of the ureter, Radiology 90: 318 (1968).

10. Talavera JM, Carney JA, and Kelalis PP: Bilateral, synchronous, primary transitional cell carcinoma of the ureter: report of 2 cases and review of literature, J. Urol. 104: 679 (1970).

11. Sozer IT: Simultaneous bilateral carcinoma of ureter, Urology 4: 217 (1974).

12. Rhame RC: Application of renal autotransplantation to the treatment of simultaneous bilateral ureteral tumours. Br. J. Urol. 45: 388 (1973).

13. Levine RL, and Airhart RA: Bilateral synchronous transitional ureteral carcinoma: two additional cases, South. Med. J . 70: $1418(1977)$ 